\title{
PRACTICAS CORPORATIVAS PARA SOCIEDADES DE CAPITAL DE RIESGO
}

\section{CORPORATE PRACTICES FOR COMPANIES RISK CAPITAL}

\author{
Saturnino A. Ugarte Silva ${ }^{1}$ \\ Decano de la Facultad de Ciencias Contables, UNMSM \\ Elsa E. Choy Zevallos ${ }^{2}$ \\ Docente Asociada de la Facultad de Ciencias Contables, UNMSM
}

(Recepción: Agosto de 2009 / Conformidad: Octubre de 2009)

\section{RESUMEN}

El cumplimiento de normativas y prácticas de gobierno no es un nuevo reto para las entidades de capital de riesgo, es más bien el dia día, puesto que la crisis de confianza de los inversionistas ha generado cambios radicales. Más que nunca es vital que las instituciones financieras consideren su cumplimiento desde un punto de vista global.

El tema está enfocado a identificar las principales transacciones que se desarrollan en el proceso de negocio identificando los riesgos y las actividades de control críticas orientadas a cubrir objetivos de control de reporte financiero.

Palabras clave: Capital de riesgo, gobierno corporativo, transparencia.

\begin{abstract}
The compliance and governance practices is not a new challenge for venture capital entities, it is rather the day day since the crisis of investor confidence has resulted in radical changes. More than ever it is vital that financial institutions consider their implementation from a global perspective.

The theme is focused on identifying major transactions taking place in the process of identifying business risks and critical control activities designed to cover control objectives of financial reporting.
\end{abstract}

Key words: Venture capital, corporate governance, transparency.

Docente en Ciencias Contables, UNMSM. Magister en Educación, UNMSM. Acutual Decano de la Facultad de Ciencias Contables, UNMSM. E-mail: decanocont@unmsm.edu.pe

2 Contadora Pública Colegiada Certificada, UNMSM. Magister en Contabilidad, UNMSM. Docente de la Unidad de Postgrado de la Facultad de Ciencias Contables, UNMSM. E-mail: eschoyz@yahoo.com 


\section{CAPITAL RIESGO}

Las entidades de capital riesgo son entidades financieras cuyo objeto principal consiste en la toma de participaciones temporales en el capital de empresas no cotizadas, generalmente no financieras y de naturaleza no inmobiliaria. El objetivo es que con la ayuda del capital de riesgo, la empresa aumente su valor y una vez madurada la inversión, el capitalista se retire obteniendo un beneficio.

El inversor de riesgo busca tomar participación en empresas que pertenezcan a sectores dinámicos de la economía, de los que se espera que tengan un crecimiento superior a la media. Una vez que el valor de la empresa se ha incrementado lo suficiente, los fondos de riesgo se retiran del negocio consolidando su rentabilidad.

El capital riesgo opera valorando el plan de negocio de los proyectos que les presentan los emprendedores mediante Comités de Inversión, que analizan la conveniencia de entrar en el accionariado de esas empresas.

\section{El capital riesgo y el desarrollo}

Por lo general el capital de riesgo es una herramienta de desarrollo económico y apoyo a empresas pequeñas tratando de crecer. Pero en vez de fijarse en el elemento de riesgo atado a este tipo de inversión, se debe concentrar más en su rol, como capital emprendedor. En los países latinoamericanos con sectores financieros menos desarrollados, el capital de riesgo tiene un papel clave en facilitar el acceso a financiamiento para la pequeña y mediana empresas, estimular una cultura emprendedora, crear trabajos y mejorar las prácticas de gobierno corporativo y los estándares de contabilidad de las empresas.

\section{Crisis financiera y capital riesgo}

Según algunos analistas, las entidades de capital riesgo habrían sido uno de los grandes contribuidores a la enorme crisis de crédito del 2008, al incrementar enormemente su apalancamiento sin ninguna necesidad. Históricamente realizaban sus inversiones sin apalancarse pero en los años previos a la crisis del 2008 realizaban operaciones con 80 con deudas y solo 20 aportados de sus recursos.

\section{GOBIERNO CORPORATIVO}

El buen gobierno corporativo está cobrando cada vez más importancia en el ámbito local e internacional debido a su reconocimiento como un valioso medio para alcanzar mercados más confiables y eficientes. En los últimos años se han establecido principios de adhesión voluntaria, realizando acuciosos estudios e implementado una serie de reformas legislativas, a fin de incentivar el desarrollo de buenas prácticas de gobierno corporativo. De esta manera, se ha reconocido el impacto directo y significativo que la implementación de dichas prácticas tienen en el valor, solidez y eficiencia de las empresas, y por tanto, en el desarrollo económico y bienestar general de los países.

Los funcionarios de entidades de capital de riesgo para cumplir a cabalidad sus funciones deben cumplir con principios éticos de: integridad, objetividad, competencia profesional y confidencialidad. Opinan que debe ser un buen profesional y esto otorgará calidad en sus servicios.

Es en el mercado público de valores, donde se ve el interés de los inversionistas en participar como alternativa de financiamiento e inversión. La consolidación del mercado de valores brindará mayores oportunidades para lograr en el futuro una mayor internacionalización de nuestro mercado. En este contexto es importante resaltar el aporte que da la Ley Sarbanes-oxley al proporcionar seguridad y transparencia de la información que se negocia en Bolsa ${ }^{1}$.

\section{Filosofia del Buen Gobierno}

Interpretando lo que expresa la Organización para la Cooperación y el Desarrollo Económico (OCDE), referida por CONASEV (2002) ${ }^{2}$; la esencia del buen gobierno institucional es crear valor para la empresa, cumpliendo las metas, objetivos y misión institucional, con la participación de los agentes internos y externos de la entidad.

Según Indacochea $(2005)^{3}$, los responsables del gobierno de las entidades consideran cada vez más la aplicación de prácticas de buen gobierno como un elemento de suma importancia para preservar el valor real de sus inversiones en el largo plazo, en la medida que conlleva a eliminar la información desigual entre

Revista Valores febrero 2006

Comisión Nacional Supervisora de empresa y Valores - CONASEV (2002) Principios de Buen gobierno para las sociedades Peruanas. Lima. Imprenta Institucional.

3 Indacochea C., Alejandro (2005) Una propuesta para mejorar las prácticas de gobierno corporativo en el Perú. Lima. CENTRUMPontificia Universidad Católica del Perú. 
quienes administran la entidad y sus inversionistas. Refuerza este objetivo la existencia de un adecuado marco legal y prácticas de supervisión eficientes que velen por la existencia de mercados transparentes que garanticen la protección del inversionista.

\section{Principios del Buen Gobierno}

Analizando a Ernst \& Young (2005) ${ }^{4}$, actualmente la receta para las universidades públicas y para todas las instituciones es el gobierno institucional, entendido como un gobierno corporativo, donde participen todos y no solamente una cúpula. La gestión corporativa explica las reglas y los procedimientos para tomar decisiones en asuntos como la prestación de servicios educativos que beneficie efectivamente a la colectividad; el manejo de los conflictos de interés; la estructura patrimonial, los esquemas de remuneración de directivos, funcionarios y trabajadores; incentivos de la institución, la adquisición del control, la revelación de información, etc.

Interpretando lo expuesto por Gonzáles $(2002)^{5}$, se puede decir que el buen gobierno, es la forma en que se dirigen y controlan las universidades y refleja las relaciones de poder entre los grupos de interés (stakeholders). También incluye los estándares mínimos adoptados por las universidades para satisfacer las necesidades de la comunidad universitaria. El propósito es contar con una recta administración (rectoría); reconocer el derecho de los usuarios, definir las responsabilidades de las autoridades; asegurar la fluidez de la información, y reconocer las relaciones con otros grupos de interés.

Los principios del buen gobierno aplicado a las universidades públicas, se inspiran en los principios del gobierno corporativo de la Organización Internacional Intergubernamental (OCDE) que reúne a los países más industrializados de economía de mercado. Los principios de la gestión corporativa para las universidades públicas, están agrupados en seis títulos:

1) Los derechos de los usuarios; para proteger y facilitar el ejercicio del derecho de los usuarios del servicio educativo;

2) Tratamiento equitativo de los servicios educativos; para asegurar el trato equitativo de todos los usuarios de universidades públicas;

3) La función de los grupos de interés en el gobierno institucional; para reconocer sus derechos establecidos por ley o acuerdos mutuos y estimular la cooperación entre la entidad y los stakeholders para hacer de la universidad una entidad rentable y sólida;

4) Comunicación y transparencia informativa; para que se presente la información de manera precisa y de modo regular acerca de todas las cuestiones materiales referentes al servicio educativo incluidos los resultados, la situación financiera, la propiedad y la gestión de la universidad;

5) La responsabilidad de las autoridades; para estipular las directrices estratégicas de la universidad, un control efectivo de la administración y la responsabilidad hacia la entidad, los usuarios y la colectividad en general;

6) Otros aspectos relacionados; para cumplir integralmente con los usuarios del servicio educativo y la colectividad en general en el marco de la responsabilidad social de las empresas.

\section{CONCLUSIONES}

- Ninguna Organización es inmune a los fraudes, y la gran mayoría son cometidos por empleados internos de las organizaciones, sacando ventaja de un sistema de control ineficaz y ausencia de buenas prácticas corporativas.

- La aplicación del Buen Gobierno Corporativo mejora la fiabilidad de la información financiera y la responsabilidad de los directivos en los procesos que garanticen una información transparente.

- La falta de información por parte de los administradores sobre gestión de riesgos puedan impedir que se logren los objetivos del negocio, asimismo la ausencia de prácticas de buen gobierno corporativo no permite contrarestar estos riegos.

\section{RECOMENDACIONES}

- Es importante que los principios de buen gobierno corporativo sea ejercida con mayor profundidad y claridad, evitando la posibilidad de escándalos financieros, y además, los directivos asuman la responsabilidad de las cifras y magnitudes de sus propias organizaciones.

- Para alcanzar múltiples propósitos en bien de toda la comunidad: Empresa, Sociedad y Estado; como agentes involucrados, es

4 Ernst \& Young (2005) Gobierno Corporativo: Diagnósticos Operativos. Lima. Curso desarrollado en la Universidad de Lima.

5 Gonzáles, Jorge (2202) Gobierno Corporativo en México. Seminario Internacional realizando en Lima. 
importante aplicar los principios de buen gobierno corporativo, permitiendo crear confianza y transparencia.

- Las inversiones hechas por empresas de Capital de Riesgo deben ser no especulativas, por lo que se sugiere establecer un periodo mínimo de años de permanencia de las inversiones para que efectivamente tenga su efecto en un apoyo real al desarrollo de nuevas empresas.

\section{REFERENCIAS BIBILIOGRÁFICAS}

1. Comisión Nacional Supervisora de empresa y Valores -CONASEV (2002) Principios de Buen gobierno para las sociedades Peruanas. Lima. Imprenta Institucional.

2. Federación de Colegios de Contadores Públicos del Perú (2004). Normas Internacionales de auditoría (NIAS) . Lima. Imprenta del Colegios de Contadores Públicos de Lima

3. Gonzáles, Jorge (2002) Gobierno Corporativo en México. Seminario Internacional, Lima.

4. Indacochea C., Alejandro (2005) Una propuesta para mejorar las prácticas de gobierno corporativo en el Perú. Lima. CENTRUM- Pontificia Universidad Católica del Perú.

5. Instituto de Auditores Internos de EspañaCoopers \& Lybrand, SA. (2004) Los Nuevos conceptos del Control Interno- INFORME COSO. Madrid. Ediciones Díaz de Santos SA.

6. Mantilla B., Samuel Alberto (traductor). Control Interno informe COSO. ECOE Ediciones, Colombia

7. Mercado de Valores. El rol de la CONASEV. Transparencia del Mercado Promoción Supervisión y Control.

\section{Electrónicas}

1. www.ccpl.org.pe

2. www.conasev.org.pe

3. www.caballerobustamante.org.pe 